\title{
Strong effect of Ecuador's conditional cash transfer program on childhood mortality from poverty-related diseases: a nationwide analysis
}

Ana L. Moncayo ${ }^{1 *}$ (D), Guillermo Granizo ${ }^{1}$, Mario J. Grijalva ${ }^{1,2}$ and Davide Rasella, 3,5

\begin{abstract}
Background: The mortality rate in children under 5 years old (U5MR) has decreased considerably in Ecuador in the last decade; however, thousands of children continue to die from causes related to poverty. A social program known as Bono de Desarrollo Humano (BDH) was created to guarantee a minimum level of consumption for families and to reduce chronic malnutrition and preventable childhood diseases. We sought to evaluate the effect of the $\mathrm{BDH}$ program on mortality of children younger than 5 years, particularly from malnutrition, diarrheal diseases, and lower respiratory tract infections.

Methods: Mortality rates and BDH coverage from 2009 to 2014 were evaluated from the 144 (of 222) Ecuadorian counties with intermediate and high quality of vital information. A multivariable regression analyses for panel data was conducted by using a negative binomial regression model with fixed effects, adjusted for all relevant demographic and socioeconomic covariates.

Results: Our research shows that for each $1 \%$ increase in $\mathrm{BDH}$ county coverage there would be a decrease in U5MR from malnutrition of $3 \%$ (RR $0.971,95 \% \mathrm{Cl} 0.953-0.989$ ). An effect of $\mathrm{BDH}$ county coverage on mortality resulting from respiratory infections was also observed (RR 0.992, 95\% Cl 0.984-0.999). The BDH also reduced hospitalization rates in children younger than 5 years, overall and for diarrhea.
\end{abstract}

Conclusions: A conditional cash transfer program such as BDH could contribute to the reduction of mortality due to causes related to poverty, such as malnutrition and respiratory infections. The coverage should be maintained -or increased in a period of economic crisis- and its implementation strengthened.

Keywords: Conditional cash transfer, Bono de Desarrollo Humano, Social determinants, Under-5 mortality rates, Ecuador

\section{Background}

Child survival has substantially improved worldwide in the past 25 years as a result of the efforts to reach the Millennium Development Goal (MDG) 4 of a two-thirds reduction in the under-five mortality rate (U5MR) between 1990 and 2015. Indeed, the global U5MR dropped 56\%, from 93 deaths per 1000 live births in 1990 to 41 in 2016 [1]. Latin

\footnotetext{
* Correspondence: amoncayo708@puce.edu.ec

${ }^{1}$ Centro de Investigación para la Salud en América Latina (CISeAL), Facultad de Ciencias Exactas y Naturales, Pontificia Universidad Católica del Ecuador, Apartado: 17-01-2184, Av. 12 de octubre 1076, Quito, Ecuador Full list of author information is available at the end of the article
}

American and the Caribbean (LAC) have reduced the under-five mortality rate by $67 \%$ since 1990 .

However, despite this progress, millions of children continue to live and die in conditions that are unacceptable. Globally, it has been described that the majority of child deaths are due to poverty and as a result of diseases that can be prevented and treated easily and economically [2]. To improve the socioeconomic conditions of disadvantaged citizens, social assistance programs have been implemented by many countries around the world. Globally, $77 \%$ and $42 \%$ of countries have unconditional and conditional cash transfers, respectively; however, significant

(c) The Author(s). 2019 Open Access This article is distributed under the terms of the Creative Commons Attribution 4.0 International License (http://creativecommons.org/licenses/by/4.0/), which permits unrestricted use, distribution, and reproduction in any medium, provided you give appropriate credit to the original author(s) and the source, provide a link to the Creative Commons license, and indicate if changes were made. The Creative Commons Public Domain Dedication waiver (http://creativecommons.org/publicdomain/zero/1.0/) applies to the data made available in this article, unless otherwise stated. 
variations in spending are observed across countries and regions [3].

Conditional Cash Transfer Programs (CCTPs) offer cash benefits to poor families that meet certain conditions associated with human capital development such as children's school attendance and health checkups. In Ecuador, the largest social assistance program is Bono de Desarrollo Humano (BDH) that began operations in 2003, preceded by the unconditional transfer program Bono Solidario, which began in 1998 [4]. In 2003, BDH represented 0.49\% of Gross Domestic Product (GDP) and from 2007 to 2013 had an upward trend reaching between 0.55 and $0.67 \%$, but then fell to $0.43 \%$ of GDP in 2014 and $0.26 \%$ in 2015 [5]. In fact, between 2007 and 2013 the usual number of beneficiary families had oscillated between 1 million and 1.2 million and the money was transferred to low-income mothers below the poverty line according to the Social Registry in all counties of the country [4]. Processes of social mobility promoted by the government and the modification of the target population to people living in extreme poverty due to fiscal constraints, caused the number of beneficiaries to decrease by $56.7 \%$ between 2013 and 2014 $(1,026,114$ beneficiary families in 2013 to 444.562 beneficiary families in 2014) $[4,6,7]$. The coverage was reduced because the changes in the eligibility criteria only involved the graduation strategy but not the entry of new potential beneficiaries [5].

Since 2013, BDH provided conditional cash transfers of US\$50 per month to target families with members under 18 years old and currently involves an additional transfer based on the number of children for up to a maximum additional US $\$ 150$ [7]. The required behaviors included both attendance by both the mother and children at preventive health check-ups and requiring a minimum percentage of attendance at school for school-age children. The aim of the program is to guarantee a minimum level of consumption for families and to contribute to the reduction of chronic malnutrition and preventable diseases for children under the age of five [7]. Because of the education condition, there is an expectation that children will have better opportunities later in life [8].

These programs have been shown to have led to a reduction in poverty [9] and to have positive effects on education [10] and health [11-13]. Programs such as Bolsa Familia (Brazil) [14] and Progresa (Mexico) [15] helped to reduce child mortality and morbidity due to causes associated with poverty, such as malnutrition and diarrhea. However, any country has implemented CCTPs heterogeneously, with different conditions and varying enforcement, with different eligibility rules and varying values in the monetary allowance, and different local factors, which can influence the effectiveness of the program. Therefore, there is an urgent need for countryspecific evaluations of CCTs.

\section{Child mortality in Ecuador}

Ecuador is among the 24 (of 81) low- and lower-middle income countries that met MDG 4 [1]. The U5MR declined in the country from 57 deaths per 1000 live births in 1990 to 21 in 2016 with an annual rate of reduction of $3.8 \%$ [1]. The poverty reduction and the government investment in health could have a positive impact on reducing U5MR. Between 2001 and 2014, high economic growth and changes in the distribution of income helped lift 1.4 million people out of poverty [5]. Labor income accounted for a decline of 10.7 percentage points in the national poverty and government transfers were responsible for a more than 3 percentage point reduction in total poverty [5]. Improved access to basic services and increased net enrollment rate in education also contributed to improved welfare [5]. The government investment in health increasing from $1.5 \%$ of GDP per year in 2007 to $4.5 \%$ in 2014 [16] ensuring coexistence of infrastructure, medical supplies and health care providers and reinforcing preventive and primary health care. In addition, since 2007, child development became a political priority with particular emphasis on the strengthening of care services and fighting against malnutrition [6]. $\mathrm{BDH}$ should have a positive impact on childhood mortality through poverty reduction, human capital development and health care utilization, which constitute one of the conditionalities of the program. $[14,15]$

In Ecuador, some studies have analyzed the role of $\mathrm{BDH}$ on child development and nutrition [17-19], but no studies to date have addressed its effect on childhood survival. Therefore, the aim of this study was evaluating the effect of $\mathrm{BDH}$ on U5MR in Ecuadorian counties, particularly mortality from poverty-related causes, including diarrhea, malnutrition and low respiratory infections (because are among the leading causes of death in children under 5 years worldwide [1]) and on some of the potential intermediate mechanisms (hospitalization rates).

\section{Methods \\ Study design}

We performed a mixed ecological study with the Ecuadorian counties as the units of analysis, during 20092014. Previous years could not be included in the study because data on $\mathrm{BDH}$ coverage were only available in a public repository since 2009. This ecological design is a combination of an ecological multiple-group and timetrend study design. We analyzed the quality of information on births and deaths for all 222 counties according to a specific criterion [20] and counties were included in the study only if they had intermediate and high quality information for the duration of the study period. This criterion considered five indicators: age-standardized mortality rate; the ratio between registered and estimated birth rates; mean relative deviation of the mortality rate; mean relative 
deviation of the birth rate; and proportion of poorly defined deaths [20]. We ordered each of the indicators from worst to best in terms of quality and a position was assigned according to the order. The final score was obtained by adding the value of the position for the 5 indicators. Finally we obtained the tertiles of the final score distribution to categorize in low, intermediate and high quality of information.

We defined as dependent variables: a) U5MR (number of deaths of children under 5 years per 1000 live births); b) cause-specific U5MR (number of deaths of children under 5 years resulting from diarrhea diseases, malnutrition or lower respiratory tract infections per 1000 live births); c) under-five hospitalization rate defined as number of children under 5 years who leave a hospital after receiving care due to diarrhea diseases, malnutrition or lower respiratory infections per 1000 live births). We used hospital discharge rates as a proxy because rates of admission to hospital were not available. The specific causes of mortality and hospitalization were created according the International Classification of Diseases (ICD), 10th revision: diarrheal diseases (A00, A01, A03, A04, A06-A09); malnutrition (E40-E46); lower respiratory infections (J10-J18, J20J22); and external causes (V01-99). External causes were included as a control variable because there is not an expected effect of the program due to these causes. All these dependent variables were obtained by direct calculation [14].

In order to evaluate different aspects of effectiveness [14], the primary explanatory variable was BDH coverage and two indicators were created: 1) coverage of the eligible population (EP): number of families enrolled in $\mathrm{BDH}$ program in a county / number of eligible families in the same county; 2) coverage of the county population $(\mathrm{CP})$ : number of individuals enrolled [obtained by multiplying the number of beneficiary families by the average family size of the county] / total population of the same county). While the first indicator of coverage evaluates the effectiveness of the intervention only on the eligible population, the second is also able to catch the externalities, or spill-over effects, that the money allowances injected - through the beneficiaries - on the overall economy of the community, as shown elsewhere [14]. Results from BDH-EP coverage are very similar (and only slightly lower) with $\mathrm{BDH}-\mathrm{CP}$ and are shown in the Additional files 1 and 2.

Based on a literature review, we identified a set of covariates as determinants of under-five mortality given their potential to confound the effect on dependent variables. The following covariates were used in the analysis $[14,21,22]$ : per capita income, illiteracy, percentage of households with inadequate sanitation, total fertility rate, number of physicians per 10,000 residents and bed rate per 1000 residents.

\section{Data sources}

The data sources for this study were the National Institute of Statistics and Census [23] (Database of births and deaths, Population Census 2001-2010, hospitalizations) and the National System of Information [24] (Integrated System of Knowledge and Social Statistics of Ecuador and Projections and demographic studies). Data were obtained at a county level, which is the lowest level with information about BDH. Except for census years 2001 and 2010, we estimated some covariates by linear interpolation or extrapolation as has been done in previous studies [14, 21, 22, 25].

\section{Statistical analyses}

We measured the effect of BDH coverages on U5MR and hospitalization rate using conditional negative binomial regression models for panel data with fixed-effects specification (counties as units of analysis with observations repeated over time) [14, 26, 27]. Negative binomial regression is used when the outcome to be analyzed is a count or a rate (with an offset variable) with a tendency to over-dispersion [26]. Fixed-effect models include a term to control for unmeasured time-invariant county characteristics (such as geography and cultural practices) and to correct for correlation of repeated measures. To evaluate the association between $\mathrm{BDH}$ coverage and U5MR (overall and specific), we calculated mortality rate ratios $(95 \% \mathrm{CI})$, both crude and adjusted for a set of demographic, social and economic determinants as covariates [14]. A time variable was also included in the models to control for secular trends of mortality. All analyses were performed using STATA version 12.0 software (Stata Corporation, College Station, TX, USA).

\section{Results}

After we applied the criteria for inclusion (vital statistics quality criterion), we selected 144 counties (64.9\%) with intermediate and high registration of vital statistics (death and live births) of the 222 Ecuadorian counties. The mean under-5 mortality rate decreased from 15.2 to 12.9 (15.1\% reduction) per 1000 live births in the studied counties, during 2009-2014. Among selected causes, there was a large decline in the U5MR attributed to diarrheal diseases (79\% reduction) (Table 1$)$. The $\mathrm{BDH}$ coverage showed a progressive decrease from 2009 to 2014 (CP: 62.5\%; EP: 63.8\%). In terms of absolute number, this meant a reduction from 1,066,892 families covered by $\mathrm{BDH}$ in 2009 to 348,404 families covered in 2014. Although, the overall under-5 hospitalization rate increased slightly during the study period, the rate by diarrheal diseases and malnutrition decreased by $1.9 \%$ and $27.6 \%$, respectively. We observed marked improvements in socioeconomic conditions during the study period. Per capita income increased by $42.1 \%$, the 
Table 1 Descriptive analysis of study variables ( $N=144)$, 2009-2014, Ecuador

\begin{tabular}{|c|c|c|c|c|c|c|c|}
\hline & 2009 & 2010 & 2011 & 2012 & 2013 & 2014 & $\begin{array}{l}\text { Percentage } \\
\text { change 2009-14 }\end{array}$ \\
\hline \multicolumn{8}{|c|}{ Mortality rate for children younger than 5 years (per 1000 livebirths) } \\
\hline Overall & $15.2(7.5)$ & $15.4(9.8)$ & $14.8(9.0)$ & $13.0(7.5)$ & $13.5(8.3)$ & $12.9(7.3)$ & -15.1 \\
\hline For diarrheal diseases & $0.70(1.88)$ & $0.64(2.51)$ & $0.52(1.72)$ & $0.47(1.39)$ & $0.31(1.42)$ & $0.15(0.45)$ & -78.6 \\
\hline For malnutrition & $0.26(0.77)$ & $0.25(0.81)$ & $0.19(0.57)$ & $0.19(0.78)$ & $0.16(0.56)$ & $0.30(0.79)$ & 15.4 \\
\hline For lower respiratory infections & $2.32(3.27)$ & $2.10(3.16)$ & $2.00(3.48)$ & $1.81(2.81)$ & $1.41(2.30)$ & $1.46(2.43)$ & -37.1 \\
\hline For external causes & $0.58(1.30)$ & $0.40(1.24)$ & $0.47(1.07)$ & $0.47(1.22)$ & $0.45(1.09)$ & $0.41(1.03)$ & -29.3 \\
\hline \multicolumn{8}{|c|}{ Hospital rate for children younger than 5 years (per 1000 livebirths) } \\
\hline Overall & $133.7(92.3)$ & $152.4(94.3)$ & $132.8(84.5)$ & $146.9(95.0)$ & $146.6(104.6)$ & $143.1(86.8)$ & 7.0 \\
\hline For diarrheal diseases & $57.0(39.5)$ & $66.4(46.3)$ & $50.0(37.3)$ & $54.8(39.1)$ & $54.5(43.8)$ & $55.9(37.9)$ & -1.9 \\
\hline For malnutrition & $2.90(7.07)$ & $3.01(4.90)$ & $2.34(2.99)$ & $2.43(3.60)$ & $2.13(4.06)$ & $2.10(3.03)$ & -27.6 \\
\hline For lower respiratory infections & $73.8(56.8)$ & $82.9(59.6)$ & $80.5(65.0)$ & $89.6(67.5)$ & $90.0(69.4)$ & $85.1(58.9)$ & 15.3 \\
\hline \multicolumn{8}{|l|}{$\mathrm{BDH}$ coverage } \\
\hline BDH coverage of the county population (\%) & $44.5(13.1)$ & $42.8(14.6)$ & $43.1(14.9)$ & $42.2(14.8)$ & $35.9(14.1)$ & $16.7(10.6)$ & -62.5 \\
\hline $\begin{array}{l}\text { BDH coverage of eligible population } \\
\text { (poor households) in the county (\%) }\end{array}$ & $63.9(10.6)$ & $61.1(12.3)$ & $61.8(12.2)$ & $60.7(12.0)$ & $51.5(12.2)$ & $23.1(11.1)$ & -63.8 \\
\hline \multicolumn{8}{|l|}{ Determinants of child mortality } \\
\hline Income per person (monthly, in USD) & $266(361)$ & $273(405)$ & $350(911)$ & $364(1015)$ & $379(1135)$ & $378(1001)$ & 42.1 \\
\hline $\begin{array}{l}\text { Proportion of households with } \\
\text { inadequate sanitation (\%) }\end{array}$ & $65.3(16.5)$ & $64.5(16.6)$ & $63.7(16.8)$ & $63.0(16.9)$ & $62.3(17.1)$ & $61.6(17.2)$ & -5.7 \\
\hline $\begin{array}{l}\text { Rate of individuals older than } 15 \text { years } \\
\text { who are illiterate }\end{array}$ & $9.95(4.79)$ & $9.70(4.70)$ & $9.47(4.62)$ & $9.24(4.55)$ & $9.02(4.48)$ & $8.80(4.41)$ & -11.6 \\
\hline Total fertility rate & $2.42(0.47)$ & $2.36(0.46)$ & $2.30(0.46)$ & $2.24(0.45)$ & $2.18(0.46)$ & $2.13(0.46)$ & -12.0 \\
\hline Hospital bed rate (per 1000 inhabitants) & $0.78(0.96)$ & $0.81(0.97)$ & $0.82(0.98)$ & $0.74(0.83)$ & $0.75(0.85)$ & $0.80(0.90)$ & 2.6 \\
\hline Hospitalization rate (per 1000 inhabitants) ${ }^{a}$ & $57.0(24.9)$ & $58.9(25.2)$ & $59.7(23.9)$ & $61.7(26.4)$ & $60.9(25.1)$ & $63.3(23.0)$ & 11.1 \\
\hline Physicians rate (per 10,000 inhabitants) & $8.68(4.46)$ & $9.37(4.79)$ & $9.93(5.29)$ & $11.10(6.27)$ & $12.05(6.52)$ & $13.25(8.75)$ & 52.6 \\
\hline
\end{tabular}

Table notes: Data are mean (SD). Causes of death were defined according to the International Classification of Diseases, 10th revision: diarrheal diseases (A00, A01, A03, A04, A06-09), malnutrition (E40-46), lower respiratory infections (J10-18, J20-22), and external causes (V01-98)

${ }^{a}$ Hospitalization rate was calculated as the number of hospital discharges for all ages and all causes of one county divided by the total population of the same county and multiplied by 1000 . $\mathrm{BDH}=$ Bono de Desarrollo Humano

percentage of households with inadequate sanitation decreased by $5.7 \%$ and the proportion of illiterate individuals decreased by $11.6 \%$. There were also reductions in the total fertility rate $(12.0 \%)$ (Table 1$)$.

Table 2 shows the crude and adjusted associations between BDH coverage (eligible and county population) and under-5 mortality rate. In the analysis, both measures of BDH coverage did not show a statistically significant association with decreasing under-5 mortality rate, even after the adjustment for socio-economic covariates.

Table 3 shows adjusted associations between $\mathrm{BDH}$ coverage on county population and under- 5 mortality rate for some relevant group of causes. The strongest effect of the $\mathrm{BDH}$ was on under-5 mortality resulting from malnutrition. One percent increase in BDH coverage was associated with a reduction of $2.9 \%$ (95\% CI $0.953-0.989)$ on under-5 mortality resulting from malnutrition in counties with intermediate and high quality of vital information. When we selected only the counties with high quality vital statistics, the observed reductions were higher (reduction of 4.8 , 95\% CI 0.922-0.983). Lower effect was observed for under-5 mortality resulting from lower respiratory infections (reduction of $0.8 \%$ (95\% CI 0.984-0.999) for counties with intermediate and high quality vital information. BDH had no effect on mortality rate caused by external causes used as a control group. The associations between $\mathrm{BDH}$ coverage on eligible population and under-5 mortality rate for some relevant group of causes are shown in Additional file 1.

Table 4 shows adjusted associations between BDH coverage on county population and under- 5 hospitalization rates. One percent increase in $\mathrm{BDH}$ coverage was associated with a reduction of $0.2 \%$ (95\% CI $0.996-0.999)$ in the overall rate of under- 5 hospitalization rates in selected counties with intermediate and high quality vital statistics. When we analyzed only counties with high quality vital information, the effect of $\mathrm{BDH}$ was not observed. In addition, $\mathrm{BDH}$ coverage reduced hospitalization rates resulting from 
Table 2 Fixed-effect negative binomial models for association between Bono de Desarrollo Humano (BDH) coverage and under-5 mortality rate, 2009-2014, Ecuador

\begin{tabular}{|c|c|c|c|c|c|c|}
\hline & Counties with intern & ediate and high qualit) & y criterion & Counties with high & uality criterion & \\
\hline & RR crude $(95 \% \mathrm{Cl})$ & RR adjusted $(95 \% \mathrm{Cl})$ & & RR crude $(95 \% \mathrm{Cl})$ & RR adjusted $(95 \% \mathrm{Cl})$ & \\
\hline $\begin{array}{l}\text { BDH coverage on } \\
\text { eligible population }\end{array}$ & $1.002(1.001-1.004)$ & $1.000(0.998-1.002)$ & & $1.003(1.001-1.004)$ & $0.999(0.997-1.002)$ & \\
\hline $\begin{array}{l}\text { BDH coverage on } \\
\text { county population }\end{array}$ & $1.004(1.002-1.006)$ & & 1.000 (0.997-1.003) & 1.005 (1.002-1.008) & & $0.998(0.993-1.002)$ \\
\hline $\begin{array}{l}\text { Hospitalization rate } \\
\text { (per } 1000 \text { inhabitants) }\end{array}$ & & $1.001(0.998-1.004)$ & 1.000 (0.998-1.004) & & $1.001(0.997-1.006)$ & $1.001(0.997-1.006)$ \\
\hline $\begin{array}{l}\text { Income per person } \\
\text { (monthly, in USD) }\end{array}$ & & $1.000(0.999-1.000)$ & 1.000 (0.999-1.000) & & $1.000(1.000-1.001)$ & $1.001(1.000-1.001)$ \\
\hline $\begin{array}{l}\text { Proportion of } \\
\text { households with } \\
\text { inadequate sanitation (\%) }\end{array}$ & & $1.009(0.985-1.034)$ & 1.009 (0.985-1.034) & & $1.010(0.984-1.038)$ & $1.010(0.983-1.037)$ \\
\hline $\begin{array}{l}\text { Rate of individuals } \\
\text { older than } 15 \text { years } \\
\text { who are illiterate }\end{array}$ & & $1.023(0.955-1.096)$ & $1.024(0.956-1.097)$ & & $1.168(1.027-1.329)$ & $1.170(1.028-1.332)$ \\
\hline Total fertility rate & & $1.351(0.932-1.958)$ & $1.353(0.933-1.962)$ & & $0.839(0.494-1.424)$ & $0.853(0.502-1.449)$ \\
\hline $\begin{array}{l}\text { Hospital bed rate } \\
\text { (per } 1000 \text { inhabitants) }\end{array}$ & & $0.992(0.936-1.053)$ & $0.993(0.936-1.054)$ & & $0.952(0.875-1.036)$ & $0.949(0.872-1.033)$ \\
\hline $\begin{array}{l}\text { Physicians rate (per } \\
10,000 \text { inhabitants) }\end{array}$ & & $1.003(0.993-1.012)$ & $1.003(0.993-1.012)$ & & $0.995(0.982-1.008)$ & $0.996(0.983-1.008)$ \\
\hline Time (year) & & $0.992(0.959-1.026)$ & $0.993(0.962-1.025)$ & & $0.982(0.942-1.023)$ & $0.977(0.937-1.019)$ \\
\hline Number of observations & 864 & 864 & 864 & 432 & 432 & 432 \\
\hline Number of counties & 144 & 144 & 144 & 72 & 72 & 72 \\
\hline
\end{tabular}

Table notes: RR Rate Ratio, Cl Confidence Interval

diarrheal diseases (reduction of 0.6, 95\% CI 0.991-0.997) in counties with intermediate and high vital information. This effect remained when we selected only counties with a high quality of vital information (reduction of $0.5,95 \%$ CI 0.990-0.999). The associations between BDH coverage on eligible population and under- 5 hospitalization rates for some relevant group of causes are shown in Additional file 2 .

\section{Discussion}

Our results show that the implementation of the $\mathrm{BDH}$ from 2009 to 2014 was associated with a reduction in U5MR from poverty-related causes such as malnutrition and lower respiratory infections at the county level. The effect remained statistically significant after we controlled for all relevant social and economic determinants. BDH also reduced rates of under- 5 hospitalizations, overall and from diarrheal diseases.

There is consistent evidence that CCTP had a positive impact on child health and nutrition outcomes, especially among the most vulnerable children. These programs have been effective in increasing the use of preventive services, consumption of healthy foods, immunization rates, and encouraging healthy behaviors [11, 13, 28].

The findings of our study are consistent with other studies that have reported an important positive impact of CCTP on childhood mortality. The Mexican program (Progresa) [15] and Brazilian program (Bolsa Familia) [22], were able to reduce infant mortality. CCTP in Bolivia increased the survival rates of birth cohorts exposed to the program by 3.5 to $16.8 \%$ [29]. In addition, a national Brazilian study showed that Bolsa Familia contributed substantially to the reduction of under-5 mortality rates, particularly of poverty-related causes such as malnutrition and diarrhea [14]. Our study, using a similar approach to the Brazilian study, also showed that $\mathrm{BDH}$ program significantly reduced under -5 mortality resulting from malnutrition and lower respiratory infections; although in Ecuador there is not a systematic process of verification of compliance with conditions such as in Brazil.

The risk of mortality from diarrhea, pneumonia and malaria are increased greatly in malnourished children, particularly those with severe acute malnutrition [30]. The contribution of CCTPs to the reduction of child undernutrition has been shown in some studies. The Colombian program Familias en Acción, was found to have improved the nutritional status of newborns and infants but only for those less than 2 years [31]. The Mexican program, Progresa was associated with a better nutritional status and greater growth of children [32, 33]. In Nicaragua, the program was found to have significantly reduced the proportion of underweight and stunted 


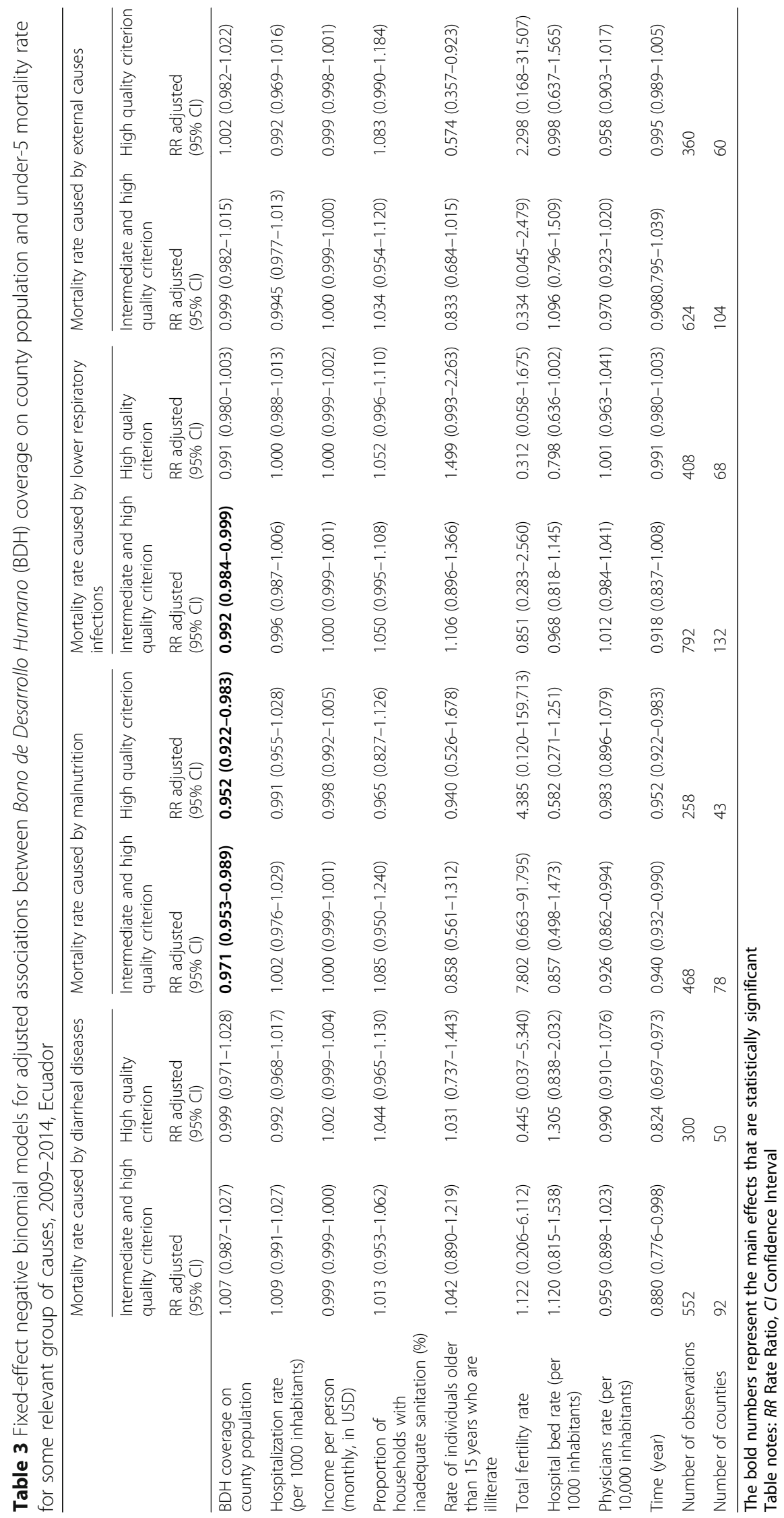




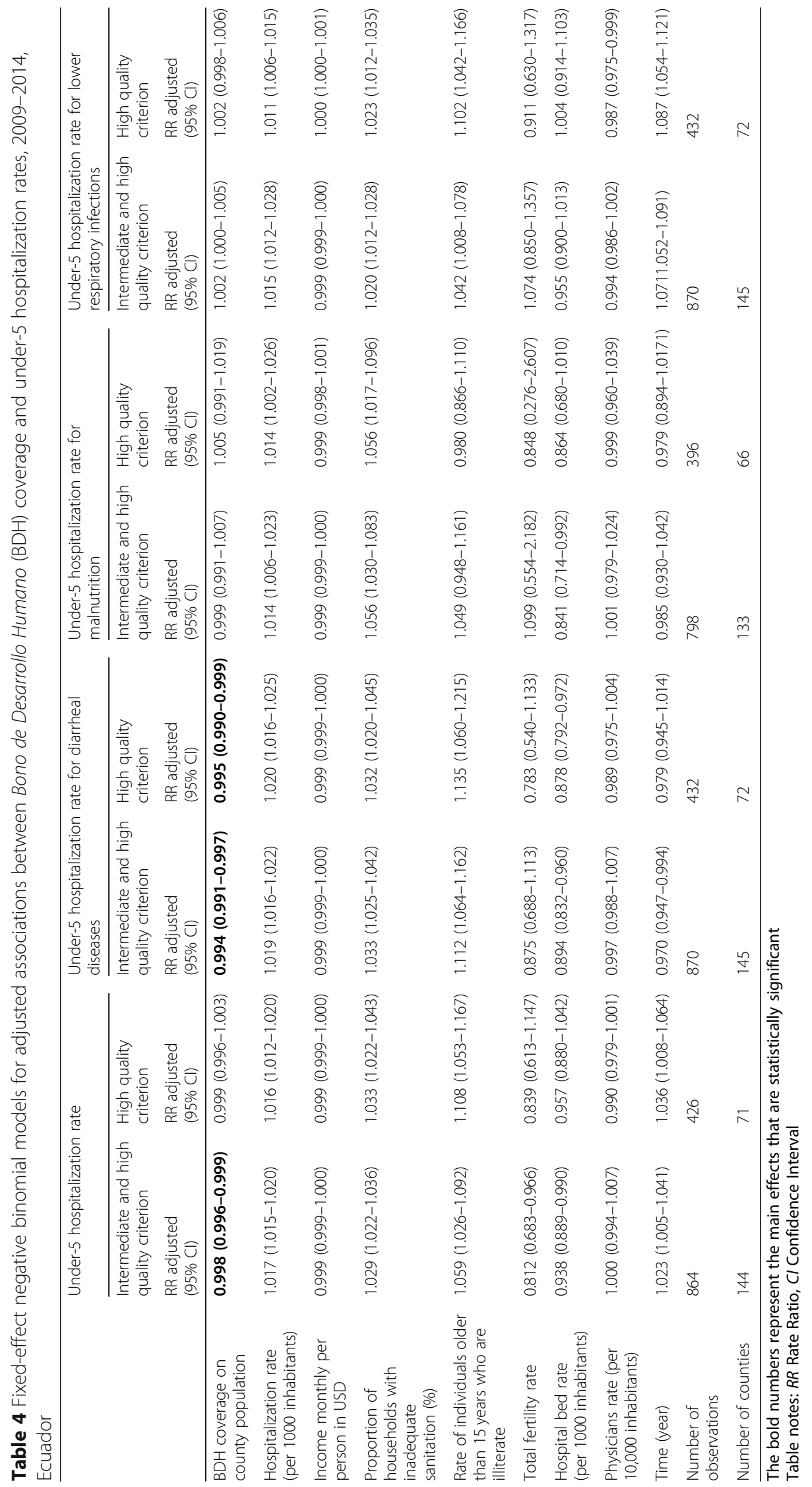


children among the beneficiaries [34]. No significant effects on height and height-for-age $\mathrm{z}$-scores were observed in program from Brazil [35] and Ecuador [18], respectively. In addition, Buser, et al. (2014) [17] showed that in Ecuador, 2 years after families lost the BDH cash transfer, which they had received for 7 years, their young children weighed less, were shorter and were more likely to be stunted than young children in families that kept the cash transfer. Research has already shown that poor families enrolled in CCTP increased food expenditures and improved food security in their households [36]. Families that benefitted from CCTPs reported increased consumption of cereals, meat, and dairy in studies from Brazil [37] and Kenya [28].

Although our results showed that the $\mathrm{BDH}$ program has a positive effect on under-5 mortality resulting from malnutrition, we did not obtain the same effect on under-5 mortality resulting from diarrhea. CCTPs are considered powerful child nutrition-sensitive interventions as they address the underlying causes of undernutrition and can enhance the effectiveness of nutritionspecific interventions [38]. However, CCT programs could have minor impact on the reduction of diarrhea outcomes since they may be more sensitive to interventions related to sanitation and hygiene.

Conditional cash transfer programs could affect survival through two main mechanisms. 1) CCT interventions lead to an increase in use of preventive health services among the poor who are underutilizing them, including prenatal care, postnatal care, health and nutrition educational activities for mothers, vaccination schedule, checkups and growth monitoring visits for children younger than 7 years [22, 34, 35, 39]. However, the benefits of improved access may be limited by the quality of existing services [36] and 2) CCT allows the household to improve health-related purchases including higher quality foods, medicines or household materials and equipment that could reduce exposure to infections $[14,36]$.

Given the important relation between CCTP and the utilization of health and educational facilities, policy makers should assess the adequacy and quality of the existing health and educational infrastructure. This is because meeting the requirements of these programs rely on the availability of basic health services and schools to meet the increased demand created by the programs.

CCTPs appear to decrease the incidence and prevalence of severe illness [36]. The Mexican program showed a $58 \%$ reduction in hospital visits for children 0 to 2 years old [39]. We found an effect of CCTP on rates of under-5 hospital rates, overall and for diarrhea. This fact could be explained by two mechanisms: 1) greater and opportune use of preventive care and higher levels of health knowledge may lead to reduce severe cases of illness that needing hospitalization and 2) decreasing the incidence of the diseases by affecting social determinants of health [36].

From 2008 to 2012, the BDH coverage has stood between 60 and 70\% in quintile Q1 and 50\% in quintile Q2 [5]. It has not been possible to reach higher coverage due to targeting accuracy and the inefficient process for updating information [5]. The Social Registry, created in 2009, obtains mainly its information through household surveys in specific districts of each county, which are selected based on their high poverty rates. Then, this information is used to determine the household's eligibility for benefits [4]. Probably, this way of data collection has resulted in the exclusion of some specific population group that being in conditions of extreme poverty and poverty are not part of the system. By 2014, the coverage of $\mathrm{BDH}$ program fell drastically because of fiscal constraints [5]. The decline in oil prices in 2014 made evident the macroeconomic vulnerabilities of Ecuador, which resulted in a decrease in public spending, including spending on social assistance [5]. Poverty reduction then stagnated as well as economic growth. The contribution of public transfers to poverty reduction decreased between 2014 and 2017, and employment and private transfers became the main drivers of poverty reduction [5]. In fact, stricter eligibility conditions were introduced to the BDH program in 2014 so that only people in extreme poverty could receive the monetary transfer [5]. This change allowed the exit of more than 600.000 beneficiaries, but it did not contemplate a process to incorporate potential new beneficiaries [6]. As a result, the coverage rates dropped substantially but the targeting improved as the number of beneficiaries of the first quintile increased [5]. The implementation of $\mathrm{BDH}$ exit strategies is required, which includes linking the beneficiaries who are not extremely poor to productive inclusion programs [5].

Our study's limitations include the ecological design and the use of the county as our unit of analysis due to data availability. In addition, we selected only counties with intermediate and high quality of vital statistics in order to improve the internal validity of our study. We observed that counties with adequate quality of vital statistics showed better socioeconomic indicators than excluded counties. Therefore, the selection of counties with vital information of adequate quality might limit the generalizability of the results to the all country. While the selection of counties with only high quality vital information since the initial year of the study would contribute to unbiased $\mathrm{BDH}$ effect estimates, its consequential reduction in number of observations would also reduce the statistical power of the study. On the other hand, the use of more relaxed criteria (intermediate and high quality) increases the number of observations but could introduce negative bias (reduction of effect) in 
$\mathrm{BDH}$ impact estimates, as already discussed elsewhere [14]. We decided to include both cases in the tables to show these effects empirically.

Another potential limitation of our study is that we were not able to test the difference between the preintervention (before 2003) and post-intervention trends, due to the limited availability of adequate quality data in the period before the implementation of the intervention. However, the differences in pre-intervention trends are also explained and adjusted by the observed variables in the models.

Finally, the linear interpolation and extrapolation of some covariates from decennial census could introduce bias. However, these estimates do not affect the results because slightly fluctuations in some structural determinants are expected during the study period.

\section{Conclusions}

CCTPs like Bono de Desarrollo Humano have great potential to improve the population health of the poorest populations. The BDH program had a positive effect on under-5 mortality resulting from malnutrition and lower respiratory infections and on under-5 hospital rates. These results are the reflection of a successful government social policy that guarantee a minimum level of consumption for families and to reduce chronic malnutrition and preventable childhood diseases. Conditional requirements should be effectively communicated, controlled and enforced with the support of an effective Primary Health System to achieve a greater effect on health outcomes.

The last revision of Social Registry and adjustment of the eligibility criteria was performed in 2014. Therefore, a large number of families were excluded from the BDH program. The coverage should be maintained -or increased in a period of economic crisis- and its implementation strengthened. In addition, these changes will require careful monitoring and evaluation of the impact of the program to support its effectiveness in the reduction of poverty and health improvements.

\section{Additional files}

Additional file 1: Fixed-effect negative binomial models for adjusted associations between Bono de Desarrollo Humano (BDH) coverage on eligible population and under-5 mortality rate for some relevant group of causes, 2009-2014, Ecuador. (DOCX 20 kb)

Additional file 2: Fixed-effect negative binomial models for adjusted associations between Bono de Desarrollo Humano (BDH) coverage on eligible population and under-5 hospitalization rates, 2009-2014, Ecuador. (DOCX $21 \mathrm{~kb})$

\section{Abbreviations}

BDH: Bono de Desarrollo Humano; CCTP: Conditional Cash Transfer Programs; Cl: Confidence Interval; CISeAL: Centro de Investigación para la Salud en América Latina; CP: County Population; EP: Eligible population;
ICD: International Classification of Diseases; LAC: Latin American and the Caribbean; MDG 4: Millennium Development Goal 4; MDG: Millennium Development Goal; PUCE: Pontificia Universidad Católica del Ecuador; RR: Rate Ratio; U5MR: Under-five mortality rate

\section{Acknowledgments}

We would like to thank the Pontificia Universidad Católica del Ecuador for their support. The content of the manuscript is solely the responsibility of the authors and does not necessarily represent the official views of the Pontificia Universidad Católica del Ecuador.

\section{Authors' contributions}

ALM and DR conceived, design and performed data analysis; they interpreted, wrote and finalized the manuscript. GG compiled and analyzed data and participated in the interpretation of results and the writing of the manuscript. MJ participated in the interpretation of results and reviewing the manuscript. All authors have read and approved the manuscript.

\section{Funding}

Funding for this work included a full scholarship awarded by Pontificia Universidad Católica (PUCE) to Guillermo Granizo, NIH-Fogarty International Center D43 Global Infectious Disease Training Grant D43TW008261 awarded to Mario Grijalva, as well as PUCE's Research Grant No.M13398 awarded to Ana Lucía Moncayo. Davide Rasella was funded by the Wellcome Trust Training Fellowships in Public Health and Tropical Medicine scheme (Grant reference number: 109949/Z/15/Z). The funders have no role in the study design, data collection, analysis, interpretation of the results, and in writing the manuscript.

\section{Availability of data and materials}

Data are with the authors (Ana L. Moncayo and Davide Rasella) and available for sharing upon request. The datasets supporting the conclusions of this article are available from public websites hosted by Ecuadorian government agencies. Birth and death data, hospitalizations, health system resources, population estimates, illiteracy and sanitation were obtained from https:// www.ecuadorencifras.gob.ec/banco-de-informacion/. Population projections were obtained from https://www.ecuadorencifras.gob.ec/proyeccionespoblacionales/. BDH coverage can be obtained from http://www. conocimientosocial.gob.ec/pages/ProgramasSociales/herramientasProgramas. jsf. Data on income was available from https://www.bce.fin.ec/index.php/ component/k2/item/763.

Ethics approval and consent to participate

No institutional review board protocol approval was needed for this study. All data were extracted from national public domain databases.

\section{Consent for publication}

Not applicable.

\section{Competing interests}

The authors declare that they have no competing interests.

\section{Author details}

${ }^{1}$ Centro de Investigación para la Salud en América Latina (CISeAL), Facultad de Ciencias Exactas y Naturales, Pontificia Universidad Católica del Ecuador, Apartado: 17-01-2184, Av. 12 de octubre 1076, Quito, Ecuador. ${ }^{2}$ Department of Biomedical Sciences, Infectious and Tropical Disease Institute, Heritage College of Osteopathic Medicine, Ohio University, Athens, Ohio, USA.

${ }^{3}$ Instituto Gonçalo Muniz, Fundação Oswaldo Cruz, Salvador, Bahia, Brazil. ${ }^{4}$ Instituto de Saúde Coletiva, Universidade Federal da Bahia, Salvador, Bahia, Brasil. ${ }^{5}$ Department of Primary Care and Public Health, Public Health Policy Evaluation Unit, School of Public Health, Imperial College London, London, UK.

Received: 31 January 2019 Accepted: 8 August 2019

Published online: 17 August 2019

\section{References}

1. UNICEF, WHO, WB, UN. Levels \& Trends in child mortality. New York: UNICEF; 2017.

2. UNICEF. Estado Mundial de la Infancia 2016. Una oportunidad para cada niño. New York: UNICEF; 2016. 
3. World Bank. Closing the gap: the state of social safety nets 2017. Washington, D.C: World Bank Group; 2017.

4. Martinez D, Borja T, Medellin N, Cueva P. Cómo funciona el Bono de Desarrollo Humano?: mejores prácticas en la implementación de Programas de Transferencias Monetarias Condicionadas en América Latina y el Caribe: BID; 2017.

5. World Bank. Ecuador-social safety net project. Washington, D.C: World Bank Group; 2019.

6. Ministerio Coordinador de Desarrollo Social. Informe de Desarrollo Social 2007-2017. In: Quito: MIES; 2017.

7. MIES. Bono de Desarrollo Humano. http://www.inclusion.gob.ec/bono-dedesarrollo-humano1/. Accessed 26 Jan 2017.

8. World Bank. World Development Report 2000/2001. Atacking poverty. New York: Oxford University Press; 2001.

9. Fiszbein F, Schady N. Conditional cash transfer: reducing present and future poverty. Washington D.C: World Bank; 2009.

10. Saavedra JE, Garcia S. Impacts of conditional cash transfer programs on educational outcomes in developing countries: a metanalysis. Santa Monica: RAND Labor and Population; 2012.

11. Ranganathan M, Lagarde M. Promoting healthy behaviours and improving health outcomes in low and middle income countries: a review of the impact of conditional cash transfer programmes. Prev Med. 2012;55(Suppl): S95-S105.

12. Gentilini U, Honorati M, Yemtsov R. The state of social safety nets 2014. Washington, D.C: World Bank Group; 2014

13. Segura-Perez S, Grajeda R, Perez-Escamilla R. Conditional cash transfer programs and the health and nutrition of Latin American countries. Rev Panam Salud Publica. 2016;40(2):124-37.

14. Rasella D, Aquino R, Santos CA, Paes-Sousa R, Barreto ML. Effect of a conditional cash transfer programme on childhood mortality: a nationwide analysis of Brazilian municipalities. Lancet. 2013;382(9886):57-64.

15. Barham T. A helathier start: the effect of conditional cash transfers on neonatal and infant mortality in rural Mexico. J Dev Econ. 2011;94:74-85.

16. World Bank. Systematic country diagnostic-Ecuador. Washington, D.C: World Bank Group; 2018.

17. Buser T. The impact of positive and negative income changes on the height and weight of young children. World Bank Econ Rev. 2016;31(3):786-808.

18. Fernald LC, Hidrobo M. Effect of Ecuador's cash transfer program (bono de Desarrollo Humano) on child development in infants and toddlers: a randomized effectiveness trial. Soc Sci Med. 2011;72(9):1437-46.

19. Paxson C, Schady N. Does money matter? The effects of cash transfer on child development. Econ Dev Cult Chang. 2007:59(1):187e229.

20. de Andrade CL, Szwarcwald CL. Socio-spatial inequalities in the adequacy of Ministry of Health data on births and deaths at the municipal level in Brazil, 2000-2002. Cad Saude Publica. 2007;23(5):1207-16.

21. Aquino R, de Oliveira NF, Barreto ML. Impact of the family health program on infant mortality in Brazilian municipalities. Am J Public Health. 2009;99(1):87-93.

22. Shei A. Brazil's conditional cash transfer program associated with declines in infant mortality rates. Health Aff (Millwood). 2013;32(7):1274-81.

23. Instituto Nacional de Estadisticas y Censos (INEC). https://www. ecuadorencifras.gob.ec/banco-de-informacion/. Accessed 01 July 2016

24. Sistema Nacional de Informacion (SNI). http://sni.gob.ec/inicio. Accessed 01 July 2016.

25. Rasella D, Aquino R, Barreto ML. Reducing childhood mortality from diarrhea and lower respiratory tract infections in Brazil. Pediatrics. 2010; 126(3):e534-40.

26. Hilbe JM. Negative Binomial Regression. Second ed. Cambridge: Cambridge University Press; 2011.

27. Frees EW. Longitudinal and Panel Data. Cambridge: Cambridge University Press; 2004

28. Davis B, Gaarder M, Handa S, Yablonski J. Evaluating the impact of cash transfer programmes in sub-Saharan Africa: an introduction to the special issue. J Dev Eff. 2012:4:1-8.

29. Celhay P, Johannsen J, Martinez S, Vidal C. Paying patients for prenatal care: the effect of a small cash transfer on stillbirths and survival: IDB Working Papers Series; 2017.

30. World Health Organization. Children: reducing mortality. http://www.who. int/mediacentre/factsheets/fs178/en/ . Accessed 02 Mar 2018.
31. Attanasio $\mathrm{O}$, Mesnard $\mathrm{A}$. The impact of a conditional cash transfer program on consumption in Colombia. In: enGender impact: the World Bank's gender impact evaluation database. Washington, D.C: World Bank; 2013.

32. Rivera JA, Sotres-Alvarez D, Shamah T, Villalpando S. Rates of growth and Anemia in infants and young children: a randomized effectiveness study. J Am Med Assoc. 2004;291:2563-70.

33. Behrman JR, Hoddinott J. Programme evaluation with unobserved heterogeneity and selective implementation: the Mexican PROGRESA impact on child nutrition. Oxf Bull Econ Stat. 2005;67:547-69.

34. Maluccio J, Flores R. Impact evaluation of a conditional cash transfer program. Washington, D.C: International Food Policy Research Institute; 2004.

35. Morris SS, Olinto P, Flores R, Nilson EA, Figueiro AC. Conditional cash transfers are associated with a small reduction in the rate of weight gain of preschool children in Northeast Brazil. J Nutr. 2004;134(9):2336-41.

36. Gaarder MM. Conditional cash transfers and health: unpacking the causal chain. J Dev Eff. 2012;2(1):6-50.

37. de Bem Lignani J, Sichieri R, Burlandy L, Salles-Costa R. Changes in food consumption among the Programa Bolsa Familia participant families in Brazil. Public Health Nutr. 2011;14(5):785-92.

38. Ruel MT, Alderman H. Nutrition-sensitive interventions and programmes: how can they help to accelerate progress in improving maternal and child nutrition? Lancet. 2013:382(9891):536-51.

39. Gertler $P$. The impact of PROGRESA on health. Washington, D.C International Food Policy Research Institute; 2000.

\section{Publisher's Note}

Springer Nature remains neutral with regard to jurisdictional claims in published maps and institutional affiliations.
Ready to submit your research? Choose BMC and benefit from:

- fast, convenient online submission

- thorough peer review by experienced researchers in your field

- rapid publication on acceptance

- support for research data, including large and complex data types

- gold Open Access which fosters wider collaboration and increased citations

- maximum visibility for your research: over $100 \mathrm{M}$ website views per year

At BMC, research is always in progress.

Learn more biomedcentral.com/submissions 